\title{
A NEW DEFINITION OF LEARNING DISABILITIES
}

\author{
Donald D. Hammill, James E. Leigh, \\ Gaye McNutt, and Stephen C. Larsen
}

Learning disabilities is a generic term that refers to a heterogeneous group of disorders manifested by significant difficulties in the acquisition and use of listening, speaking, reading, writing, reasoning or mathematical abilities. These disorders are intrinsic to the individual and presumed to be due to central nervous system dysfunction. Even though a learning disability may occur concomitantly with other handicapping conditions (e.g., sensory impairment, mental retardation, social and emotional disturbance) or en. vironmental influences (e.g., cultural differences, insufficient/inappropriate instruction, psychogenic factors), it is not the direct result of those conditions or influences.

In 1981, after prolonged discussion and compromise, the representatives of the six organizations that constitute the National Joint Committee for Learning Disabilities (NJCLD) reached unanimous agreement on a new definition of learning disabilities. The NJCLD comprises representatives from: the American Speech-Language-Hearing Association (ASHA), the Association for Children and Adults with Learning Disabilities (ACLD), the Council for Learning Disabilities (CLD), the Division for Children with Communication Disorders (DCCD), the International Reading Association (IRA), and The Orton Dyslexia Society (formerly The Orton Society).

As the definition will undoubtedly receive considerable attention from the professional community, we felt that the membership of CLD would be interested in knowing (a) the reasons why the NJCLD considered a new statement to be needed; (b) the procedures followed by the Committee in generating the definition; (c) the Committee's intended meaning for each phrase in the definition; and (d) the current status of the definition. We would like to point out that this article is based on our participation (as CLD representatives) in the NJCLD meetings. To ensure accuracy, we have asked all NJCLD members who participated in the formulation of this definition to review this manuscript prior to its publication.

\section{THE NEED FOR A NEW DEFINITION}

Before the 1960s, professionals who wanted to refer to the collection of disorders later to become known as learning disabilities used such terms as minimal brain dysfunction/injury, psychoneurological learning disorders, dyslexia, or perceptual handicap. After that time, the

DONALD D. HAMMILL, Ed.D., is Executive Director, Society for Learning Disabilities and Remedial Education, Austin, TX.

JAMES E. LEIGH, Ph.D., is Assistant Professor, Department of Special Education, University of Missouri - Columbia.

GAYE McNUTT, Ph.D., is Assistant Professor, Department of Special Education, University of Oklahoma, Norman.

STEPHEN C. LARSEN, Ed.D., is Professor, Department of Special Education, University of Texas at Austin. 
term learning disabilities became popular, then prevalent, due in no small part to the efforts of Dr. Samuel Kirk. (See Kirk and Gallagher, 1979, and Wiederholt, 1974, for reviews of the origin of the term learning disabilities.) The growing use of the term prompted the development of many definitions, with those of Kirk and Bateman (1962), Myklebust (1963), Bateman (1964), and the National Advisory Committee on Handicapped Children (1968) being among the most notable.

Of these, the latter was decidedly the most influential. This definition was included in Public Law 91-230 (Children with Specific Learning Disabilities Act of 1969, The Elementary and Secondary Amendments of 1969) and was changed only slightly for inclusion in PL 94-142 (The Education for All Handicapped Children Act of 1975). The PL 94-142 definition reads as follows: (The definition in the 1977 Federal Register varies only in the initial wording)

The term "children with specific learning disabilities" means those children who have a disorder in one or more of the basic psychological processes involved in understanding or in using language, spoken or written, which disorder may manifest itself in imperfect ability to listen, think, speak, read, write, spell, or do mathematical calculations. Such disorders include such conditions as perceptual handicaps, brain injury, minimal brain dysfunction, dyslexia, and developmental aphasia. Such term does not include children who have learning problems which are primarily the result of visual, hearing, or motor handicaps, of mental retardation, of emotional disturbance, or environmental, cultural, or economic disadvantage.

One of the most frequently and consistently cited criticisms leveled against the LD field has been the lack of consensus among professionals concerning a definition of the term learning disabilities. The 1968 National Advisory Committee's definition enjoyed an acceptance that exceeded all others. Yet, even the passage of PL 94-142, which gave the definition an aura of officiality, did not eliminate the widespread dissatisfaction and disagreement regarding the definitional issue.

The modified 1968 definition which appeared in PL 94-142 has served the educational community well in many ways, especially by providing a basis for federal and state funding of instructional services for school-aged children. However, the NJCLD believed strongly that the definition had inherent weaknesses that made it unacceptable as a definition that could be used to delimit a field as broad and complex as that of learning disabilities. The reasons for this belief are mentioned briefly below. Some of these problems are also discussed in the NJCLD's position paper (1981) on the new LD definition.

1. Because learning disabilities may occur in individuals of all ages, the use of the term children in the 1968 and PL 94-142 definitions is unnecessarily restrictive. Since the enactment of the law, a major trend in the field has been the development of secondary-level and adult programs as described by Alley and Deshler (1979), Marsh, Gearheart, and Gearheart (1978), and Wiederholt (1978). The significance of this trend is indicated further by recent initiatives of the Association for Children and Adults with Learning Disabilities (previously the Association for Children with Learning Disabilities) and the Council for Learning Disabilities (previously the Division for Children with Learning Disabilities) to change their names in order to reflect concern for the entire population of learning disabled individuals. Also, there are now several new organizations for adults with learning disabilities, a population not specifically mentioned in the PL 94-142 definition (e.g., LAUNCH, an acronym for Leadership, Action, Unity, Nurturing, Citizenship, and Harmony).

2. The inclusion of the phrase basic psychological processes has generated extensive and possibly needless debate in the field. The original and legitimate intent of the phrase seems to have been to underscore the intrinsic nature of learning disabilities while simultaneously shifting the focus away from the neurological emphasis so predominant in the early days of LD. The National Advisory Committee on Handicapped Children recognized the need to differentiate clearly between learning disabilities caused by internal factors, whether psychological or neurological, and other learning problems caused by environmental influences, e.g., poor or 
insufficient instruction. However, the phrase basic psychological processes regrettably became associated with the "mentalistic process" and "perceptual-motor ability" training programs that evolved from the theoretical models which were popular at the time when the definition was developed and implemented.

The presence of this particular phrase in the definition led to a polarization of professionals into two different and often disputing groups-those who advocated the direct instruction of reading, writing, talking, etc., and those who advocated the training of certain psychocognitive abilities presumed to underlie or greatly influence proficiency in reading, writing, talking, etc. These abilities were called processing abilities and included such psychocognitive constructs as memory, perception, modality, closure, and sequencing.

The relative merits of these two orientations need not concern us here. What is important to the discussion of the definition is that the majority of both groups would probably agree with the original intention of the phrase: namely, that the cause of the learning problem is intrinsic to the affected person. It is the wording of the phrase that has triggered so much unnecessary controversy with regard to defining LD. Whether direct or process instruction is preferable is indeed an important issue; but the issue pertains to the topic of curriculum, not to definition.

3. In the PL 94-142 definition, "spelling" is listed as a manifestation of a specific disorder. In a statement clarifying the specific areas of achievement to be evaluated, the U.S. Office of Education (1977) acknowledged that although “...'spelling' is listed in the statute, the components of spelling can be assumed under the other seven areas of function. Spelling as a category per se has been deleted from the final regulations" (p. 65085); however, it remains in the official definition. The redundant inclusion of spelling, which is typically considered to be subsumed under written expression, should not be included in definitions of LD.

4. The definition of learning disabilities is not enhanced by the list of "conditions" which the term purportedly includes (i.e., "perceptual handicaps, brain injury, minimal brain dysfunction, dyslexia, and developmental aphasia"). These terms, which are supposed to help clarify the definition, merely add to the confusion. Professionals in medicine, psychology, speech pathology, and reading have argued long and bitterly over the precise meanings of these labels. To include such ill-defined terms in an LD definition only invites further controversy, confusion, and misinterpretations.

5. The wording of the final, i.e., the "exclusion," clause has contributed to the widespread misconception that learning disabilities can occur neither in conjunction with other handicapping conditions nor in the presence of "environmental, cultural, or economic disadvantage." Such an interpretation is simply not accurate; nor is it the original intention of the clause. A careful reading of the clause leads to the interpretation that learning disabilities cannot be the direct or primary result of the conditions and situations listed. Presumably, they can be secondary or in addition to those conditions and situations. For instance, consider a blind 14-yearold with impairment of spoken language as a consequence of a brain tumor. This is a clear-cut example of a multiply handicapped LD individual; whether the youngster were disadvantaged in any way would be irrelevant to the diagnosis, because it bears no relationship to the loss of language. Once again, the objection to the PL 94-142 definition is directed more to its ambiguity than to its intention.

To be sure, during the NJCLD's deliberations, many other shortcomings of the PL 94-142 and other definitions were aired; but to us, those just mentioned were the most crucial. For those and other reasons, the Committee felt that a new definition would be desirable.

\section{PROCEDURES FOLLOWED IN THE DEVELOPMENT OF THE NEW DEFINITION}

Having resolved to undertake the development of a new definition, the Committee had to decide on the exact nature of a definition. The members agreed that a definition was basically a theoretical statement specifying the delimiting characteristics of conditions called learning disabilities. These attributes had to be broad enough to include all known examples of learning disabilities, yet narrow enough to permit the distinction of learning disabilities from other condi- 
tions. The purpose of the definition was to establish learning disabilities theoretically - not to set up specific operational criteria for identifying individual cases. Important as operational criteria may be to school placement, research subject selection, and funding practices, the theoretical statement must come first, because it serves as a guide for generating actual objective identification procedures. To be practical, the abstract contents of the definition must be implemented in administrative rules and regulations.

In February, 1980, with these points in mind, the NJCLD authorized a three-member subcommittee to prepare a preliminary draft of the definition. The subcommittee presented its work to the full NJCLD in September, 1980. After two days of intense discussion, all differences among NJCLD members were reduced to tolerable levels and the definition was agreed to unanimously. In January, 1981, the NJCLD held another meeting at which the definition received further refinement. Since September, 1980, the respective governing boards of the organizations represented on the NJCLD have been considering the definition. The results of their considerations are reviewed in the final section of this report.

Too often, some document or position statement is said to be the work of a "committee," making it appear as if the piece were the creation of some abstract, faceless being. In fact, committees are composed of individual people. The names of those persons who helped write the definition and who subsequently recommended it to their parent organizations are listed below.

1. ASHA: Anthony Bashir, Katharine G. Butler, Stan Dublinske, Hal McGrady

2. ACLD: Robert C. Reed, Sylvia Richardson, Alice Scogins, Shari Sowards

3. CLD: Donald D. Hammill, Stephen C. Larsen, James Leigh, Gaye McNutt

4. DCCD: Clare Maisel, Joel Stark, Rhonda Work

5. IRA: Jules Abrams, Jack Cassidy, Ralph Staiger

6. Orton: Drake D. Duane, William Ellis, Mary Lee Enfield, Linda M. Frank

\section{THE COMMITTEE'S INTENTION}

Even the best worded definitions are subject to inadvertent misinterpretation. To avoid, or at least to minimize, this possibility we wish to discuss the new definition (quoted at the beginning of this article) on a phrase-by-phrase basis. In this way, we can express the intention of the NJCLD on the critical elements of the definition.

"Learning disabilities is a generic term"

The Committee felt that learning disabilities was a global ("generic") term under which a variety of specific disorders could be reasonably grouped.

"that refers to a heterogeneous group of disorders"

The disorders grouped under the learning disability label are thought to be specific and different in kind, i.e., they are "heterogeneous" in nature. This phrase implies that the specific causes of the disorders are also many and dissimilar.

"manifested by significant difficulties"

The effects of the disorders on an individual are detrimental to a consequential degree; that is, their presence handicaps and seriously limits the performance of some key ability. Because the NJCLD was concerned that "learning disabled" is often used as a synonym for "mildly handicapped," the Committee wanted to emphasize that the presence of learning disabilities in an individual can be as debilitating as the presence of cerebral palsy, mental defect, blindness, or any other handicapping condition.

"in the acquisition and use of listening, speaking, reading, writing, reasoning or mathematical abilities."

To be considered learning disabled, an individual's disorder has to result in serious impairment of one or more of the listed abilities.

"These disorders are intrinsic to the individual"

This phrase means that the source of the disorder is to be found within the person who is affected. The disability is not imposed on the individual as a consequence of economic deprivation, poor child-rearing practices, faulty school instruction, societal pressures, cultural dif- 
ferences, etc. Where present, such factors may complicate treatment, but they are not considered to be the cause of the learning disability.

"and presumed to be due to central nervous system dysfunction."

The cause of the learning disability is a known or presumed dysfunction in the central nervous system. Such dysfunctions may be by-products of traumatic damage to tissues, inherited factors, biochemical insufficiencies or imbalances, or other similar conditions that affect the central nervous system. The phrase is intended to spell out clearly the intent behind the statement that learning disabilities are intrinsic to the individual. Certainly, a large segment of the learning disabilities community would agree that the cause of the conditions known as specific learning disabilities is some type of malfunction within the central nervous system. (See Adelman, 1979; Bryan \& Bryan, 1978; Chalfant \& Scheffelin, 1969; Cruickshank, 1976; Hallahan \& Cruickshank, 1973; Johnson \& Myklebust, 1967; Kephart, 1960; Kirk \& Gallagher, 1979; Orton, 1939; Reid \& Hresko, 1981; Strauss \& Lehtinen, 1947; among many, many others.)

The Committee was quick to point out that in some cases a causal relationship between linguistic or academic problems and CNS dysfunction is easy to determine, but that in most cases it is not so obvious. For example, the problem-cause relationship is apparent in cases where the individual evidences a noticeable reduction of language proficiency after experiencing a stroke or brain injury of some sort, i.e., where the difficulty is suddenly "acquired." The vast majority of LD cases, however, are "developmental". That is, the problems emerge slowly and simultaneously as the child attempts to develop or master some ability, e.g., reading. In these latter types, attempts to determine the cause of the problem become difficult and are often speculative.

Consequently, the Committee agreed that hard evidence of organicity did not have to be present in order to diagnose a person as learning disabled, but that no person should be labelled LD unless CNS dysfunction was the suspected cause. Certainly, cases should not be diagnosed as LD where the cause is known or thought to be something other than CNS dysfunction.

"Even though a learning disability may occur concomitantly with other handicapping conditions (e.g., sensory impairment, mental retardation, social and emotional disturbance) or en. vironmental influences (e.g., cultural differences, insufficient/inappropriate instruction, psychogenic factors),"

This simply means that learning disabilities are found among all kinds of people, including the mentally retarded and the economically disadvantaged.

"it is not the direct result of those conditions or influences."

This is a clear restatement of the belief that learning disabilities are different from other handicapping conditions and that they arise neither from the presence of them nor from environmental influences.

\section{CURRENT STATUS OF THE DEFINITION}

For the definition to become an official document of the NJCLD, it has to receive the endorsement of the governing boards of all six organizations represented on the Committee. If approved by all six groups, the definition will be known as The Definition of the National Joint Committee for Learning Disabilities. Should one or more of the organizations choose not to endorse the definition, it will become the official definition of those groups that have embraced it.

To date, the definition has been accepted by the governing boards of the Council for Learning Disabilities (formerly DCLD), the International Reading Association, the Division for Children with Communication Disorders, and The Orton Dyslexia Society. The Executive Board of the American Speech- Language- Hearing Association has approved the definition, which will next be considered by the legislative council for final approval. The Board of the Association for Children and Adults with Learning Disabilities disapproved the definition as 
written. In addition to the NJCLD organizations, two other groups in the LD field are presently considering adoption of the definition, i.e., the Society for Learning Disabilities and Remedial Education and $\mathrm{LAUNCH}$, a coalition for learning disabled adults.

\section{TO CONCLUDE}

The preceding has been a discussion of why and how the NJCLD came to propose a new definition of learning disabilities. The very activity by which the definition came about was both instructive and beneficial to all participants. The fact that the NJCLD members who are representative of parents and professionals, of direct and process approaches to instruction, and of differing (and often competing) disciplines could meet, agree to a task, deliberate, argue, reconsider, compromise, and eventually reach a unanimous consensus is in itself an unprecedented happening.

The NJCLD members are the first to acknowledge that the proposed definition is not perfect. Yet, they are convinced that the definition is a substantial improvement over existing ones. They never intended to write the ultimate definition, only a better one; and, doubtlessly, in the years to come, their effort will be discarded in favor of a newer, improved version. Until then, the Committee believes that the proposed definition is the best one available and recommends that it be considered as a theoretical statement about the nature of learning disabilities.

\section{REFERENCES}

Adelman, H.S. Diagnostic classification of LD: Research and ethical perspectives as related to practice. Learning Disability Quarterly, 1979, 2 (3), 5-16.

Alley, G., \& Deshler, D. Teaching the learning disabled adolescent: Strategies and methods. Denver: Love Publishing, 1979.

Bateman, B. Learning disabilities-Yesterday, today and tomorrow. Exceptional Children, 1964, 31, 167-177.

Bryan, T.H., \& Bryan, J.H. Understanding learning disabilities (2nd ed.). Sherman Oaks, CA: Alfred, 1978.

Chalfant, J.C., \& Scheffelin, M.A. Central processing dysfunctions in children: A review of research. NINDS Monograph, No. 9. Bethesda, MD: U.S. Department of Health, Education, and Welfare, 1969.

Cruickshank, W.M. William M. Cruickshank. In J.M. Kauffman \& D.P. Hallahan (Eds.), Teaching children with learning disabilities: Personal perspectives. Columbus, OH: Merrill, 1976.

Hallahan, D.P., \& Cruickshank, W.M. Psychoeducational foundations of learning disabilities. Englewood Cliffs, NJ: Prentice-Hall, 1973.

Johnson, D.J., \& Myklebust, H.R. Learning disabilities: Educational principles and practices. New York: Grune \& Stratton, 1967.

Kephart, N.C. The slow learner in the classroom. Columbus, OH: Merrill, 1960.

Kirk, S.A., \& Bateman, B. Diagnosis and remediation of learning disabilities. Exceptional Children, 1962, 29, 73-78.

Kirk, S.A., \& Gallagher, J.J. Educating exceptional children (3rd ed.). Boston: Houghton Mifflin, 1979.

Marsh, G.E., Gearheart, C.K., \& Gearheart, B.R. The learning disabled adolescent: Program alternatives in the secondary school. St. Louis: C.V. Mosby, 1978.

Myklebust, H.R. Psychoneurological learning disorders in children. In S.A. Kirk \& W. Becker (Eds.), Conference on children with minimal brain impairment. Urbana, IL: University of Illinois Press, 1963.

National Advisory Committee on Handicapped Children. Special education for handicapped children. First Annual Report. Washington, DC: U.S. Department of Health, Education, and Welfare, January 31, 1968.

National Joint Committee for Learning Disabilities. Learning disabilities: Issues on definition. Unpublished manuscript, 1981. (Available from Drake Duane, NJCLD Chairperson, c/o The Orton Dyslexia Society, 8415 Bellona Lane, Towson, Maryland 21204).

Office of Education. Procedures for evaluating specific learning disabilities. Federal Register, 1977, 42, $65082-65085$.

Orton, S. Reading, writing and speech problems in children. New York: Norton, 1939.

Reid, D.K., \& Hresko, W.P. A cognitive approach to learning disabilities. New York: McGraw-Hill, 1981. 
Strauss, A.A., \& Lehtinen, L. Psychopathology and education of the brain-injured child. New York: Grune \& Stratton, 1947.

Wiederholt, J.L. Historical perspectives on the education of the learning disabled. In L. Mann \& D. A. Sabatino (Eds.), The second review of special education. Philadelphia: JSE Press, 1974.

Wiederholt, J.L. Adolescents with learning disabilities: The problem in perspective. In L. Mann, L. Goodman, \& J.L. Wiederholt (Eds.), Teaching the learning disabled adolescent. Boston: Houghton Mifflin, 1978.

Requests for reprints should be addressed to: Gaye McNutt, Dept. of Special Education, University of Oklahoma, Norman, OK 73069.

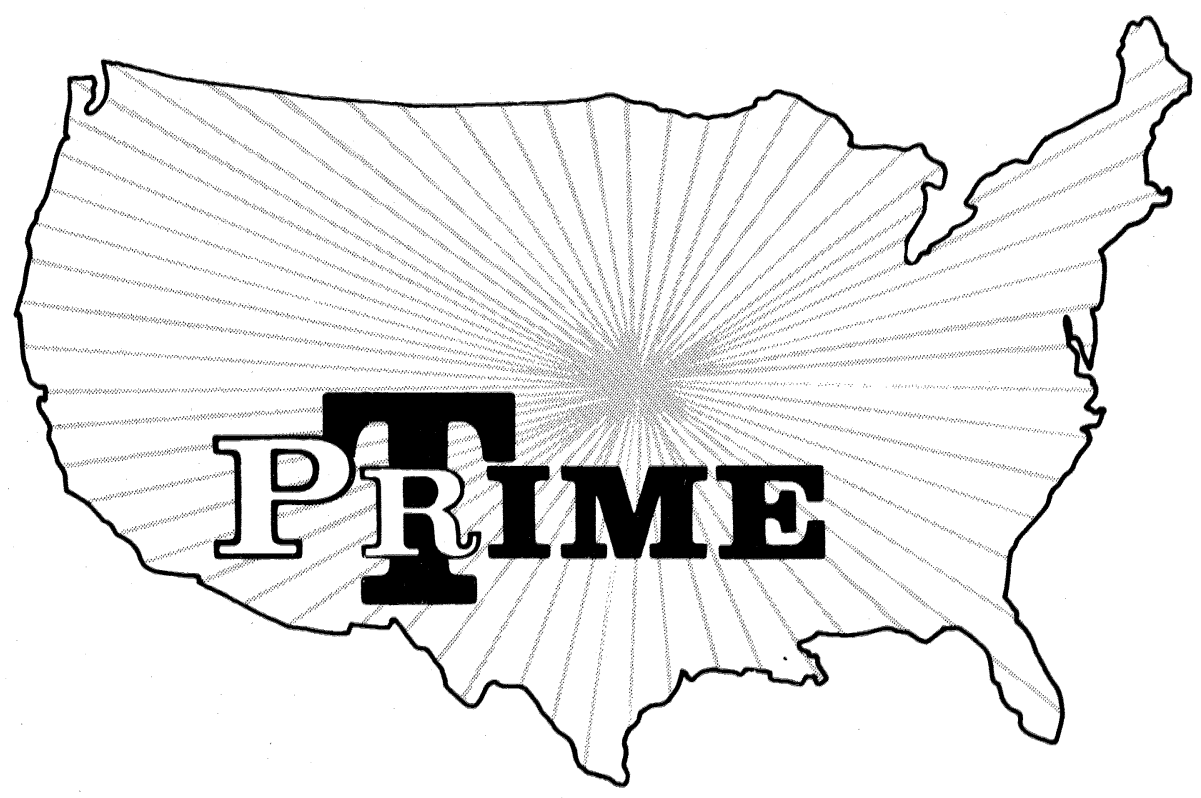

International Conference

On

Learning Disabilities

Kansas City, Missouri

OCTOBER 7 - 9, 1982 